\title{
Extending the Association Between Leader-Member Exchange Differentiation and Safety Performance: A Moderated Mediation Model
}

\author{
Naiwen Li ${ }^{1}$ \\ Shiwang Bao' \\ Sobia Naseem (iD) ${ }^{2}$ \\ Muddassar Sarfraz (D) ${ }^{3}$ \\ Muhammad Mohsin (D) ${ }^{4}$ \\ 'School of Business Management, \\ Liaoning Technical University, Huludao, \\ I25 I05, People's Republic of China; \\ ${ }^{2}$ School of Economics and Management, \\ Shijiazhuang Tiedao University, \\ Shijiazhuang, People's Republic of China; \\ ${ }^{3}$ Binjiang College, Nanjing University of \\ Information Science and Technology, \\ Wuxi, Jiangsu, People's Republic of China; \\ ${ }^{4}$ School of Business, Hunan University of \\ Humanities, Science and Technology, \\ Hunan, People's Republic of China
}

Purpose: This study examines and analyses the impact of leader-member exchange differentiation (LMXD) on employee safety performance.

Methods: A quantitative study was conducted on a sample of 357 Chinese construction industry employees through a structured questionnaire. The research hypothesis was tested by using the structural equation modelling (SEM) technique.

Results: The results showed that LMXD could directly and positively affect the negative emotions and indirectly affect the safety performance of employees through the mediating effect of negative emotions and work engagement. Interpersonal trust has a moderating impact on the relationship between LMXD and negative emotions.

Conclusion: This study contributes to the literature on organizational behavior. Employee workplace safety is a great challenge in the construction industry. Enterprises should pay attention to the negative impact of LMXD. A fair working environment has significant importance to the employee's safety.

Keywords: leader-member exchange differentiation, negative emotions, work engagement, interpersonal trust, safety performance

\section{Introduction}

Over the years, the foundation of work environment safety has remained the biggest challenge for industry experts and professionals. The incredible increase in injuries and accidents has made safety performance a distinct factor affecting occupational health and safety outcomes. Safety climate alludes to the organization that values the safety concerns while having the security policies embedded within the organization, thereby accomplishing successful safety outcomes.

Indeed, the organizational history emphasizes the significance of reinforcing the secure climate for ensuring environmental assurance by impeding unfavorable consequences. ${ }^{1}$ Based on the research conducted on occupational safety, the findings illustrate that more than 100,000 production safety accidents in the Transportation and Warehouse sector (ie, truck and freight) were recorded in 2018. Hence, for governing the unsafe behavior, a safety performance mechanism needs to be embraced for curtailing the adversity in human lives while ensuring workers' well-being.

Finding illustrates that combating the difficulties concerning climate safety and reducing the number of catastrophic events is essential in understanding the highrisk behavior leading to massive calamity (ie, fatal injuries). Thus, creating a typology for identifying the organization's approaches and behaviors concerning
Correspondence: Muddassar Sarfraz; Muhammad Mohsin

Email muddassar.sarfraz@gmail.com; mohsinlatifntu@gmail.com 
leadership characteristics is vital for ensuring environmental safety. Given the explanation, leadership behaviors play a critical role in building the leader-employee relationship. Subsequently, for bolstering safety performance, LeaderMember Exchange differentiation, coined from the primes of LMX theory (ie, leader- subordinate relationship), contemplates the relationship by symbolizing the effect of leader's attitude influencing the employees' performance.

LMX differentiation is a novel configurable approach influencing task performance and organization outcome. It demonstrates that the difference between leadersubordinate relationships increases safety concerns while increasing the chances of injuries and accidents. Among all the imperative factors improving the organization's safety outcome, this multi-level dual-process (eg, LMXD) is a dominant factor affecting occupational health and safety.

Researchers have confirmed the importance of the relationship between leaders and followers in the workplace. $^{2}$ The leader-member exchange theory emphasizes that leaders should develop high-quality relationships with followers. Still, due to the limited energy of leaders, it is challenging to develop high-quality relationships with all followers, so employees will be treated differently by leaders, which is the leadership member exchange differentiation (LMXD). ${ }^{3}$ Due to the increasing prevalence of leader-member exchange differences in the workplace, the impact of leader-member exchange differences on employee safety performance needs more research.

Previous studies have not paid enough attention to the role of emotion in the explanation mechanism of LMXD and behaviour outcome. According to the affective events theory, an individual's experience of the work environment and work events will stimulate his emotional response and affect his attitude and behaviour. ${ }^{4}$ As leaders cannot develop high-quality exchange relationships with all employees, the unfair allocation of resources is widespread in organizations, and the dissatisfaction caused by the unfair treatment of employees often leads to behavioural disorders. Therefore, this paper believes that negative emotions play a mediating role between LMXD and safety performance.

As a kind of work attitude, work engagement plays a vital role in the workplace. Previous studies have confirmed the relationship between employee performance and work attitude, ${ }^{5}$ and a good work attitude is conducive to employee performance improvement. Maintaining a high-quality exchange relationship between leaders and members will make employees expect the organization and arouse positive working attitudes. ${ }^{6}$ The more prominent the difference between leaders and followers in exchange, it indicates that it is difficult for employees to be treated equally by leaders, and the organization's resource allocation is more dependent on leaders' personal preferences, which will dampen employees' enthusiasm and commitment to work, and have a negative impact on performance. Therefore, this paper introduces two mediating variables, negative emotions and work engagement, to explore the mechanism of action between LMXD and safety performance. The study sheds light on the theory of LMX differentiation affecting safety performance. The weak leadersubordinate relationship breaks down the supportive safety atmosphere, thereby hampering the organization's safety climate. Hence, it is essential to study reliable predictive factors affecting environmental safety performance. As a result, uncommon consideration should be paid to the predictive model (ie, LMXD), leading to better implementation of safety programs within the field of occupational security. ${ }^{7}$

In addition, this study attempts to explore the moderating effect of interpersonal trust. The process of LMXD acting on negative emotions will also be affected by psychological factors. As one of the psychological factors, interpersonal trust reflects an individual's trust in the external environment and others. ${ }^{8}$ The external manifestation of LMXD is the differentiation of resource allocation. ${ }^{9}$ For employees with low interpersonal trust, this differentiated resource allocation will increase their perception of unfairness, thus increasing their feelings of jealousy and dissatisfaction.

On the contrary, employees with high interpersonal trust are more likely to have a sense of security for the organization ${ }^{10}$ and have a higher willingness to take risks ${ }^{11}$ so that they can work with a positive attitude. Existing studies have shown that trust can regulate the influence of major determinants on outcomes by influencing an individual's assessment of future behaviour or interpreting the past behaviour of another party. ${ }^{12}$ Therefore, the interpersonal trust of employees may regulate the impact of LMXD on negative emotions to some extent.

Based on the affective events theory, this study introduces negative emotions and work engagement as mediating variables and interpersonal trust as moderating variables to explore the impact of LMXD on safety 
performance to provide a reference for enterprise management practices. Thus, this study sought to make several contributions to the existing body of knowledge. Firstly, this study is among the few studies that have attempted to investigate the role of LXMD in predicting safety performance. ${ }^{13}$ Secondly, this investigation has considered negative emotions a mediating mechanism between the LMXD and safety performance which is a unique contribution of the study. And adds essential links into the existing literature by anticipating the future call of Gooty, Thomas et al ${ }^{14}$ to develop more theoretical development concerning negative emotions. Thirdly, this study has identified a missing thread related to construction workers' LMX and safety performance. $\mathrm{He}^{13}$ conceptualized work engagement to enhance safety performance in the construction industry.

\section{Literature Review and Research Hypothesis \\ LMXD and Safety Performance}

LMXD refers to the difference between team members and the same leader in the quality of the exchange relationship between leader and employees. ${ }^{15}$ If a leader treats employees in different ways, individuals might develop stress, which can drive them into negative feelings and feel scared, ashamed, and depressed. ${ }^{16}$ Moreover, this leadership discrimination in differentiated behaviour might trigger them to be hostile at the workplace, resulting in drastic consequences for others. The safety performance of individuals is likely to be shattered in the construction industry. Safety performance refers to the degree of achievement of safety tasks, divided into safety compliance and participation. ${ }^{17}$ Existing studies have not discussed the relationship between LMXD and safety performance, but relevant studies show that there may be a negative relationship between LMXD and safety performance. According to the leader-member exchange theory, due to limited energy, leaders will only maintain highquality exchange relationships with a few employees, who will therefore get more promotion opportunities and resource tilt. ${ }^{18}$ According to the conservation of resource theory, they will try their best to obtain, preserve and maintain their limited resources. ${ }^{19}$ Therefore, a high-quality leadermember exchange relationship is one of the resources that employees pursue. However, as people's energy and time are limited, when employees invest in developing high-quality exchange relationships with their leaders, they will ignore the improvement of their work ability and ultimately damage their work quality and performance. ${ }^{20}$ Based on this, hypothesis $\mathrm{H} 1$ is proposed:

H1: LMXD has a significant negative impact on safety performance.

\section{The Mediating Role of Negative Emotions}

Negative emotions are a series of unpleasant emotional feelings and reactions such as indignation, tension, and fear produced by individuals psychologically and physically. ${ }^{21}$ The working atmosphere will affect employees' emotional feelings and expressions in daily work. ${ }^{22}$ Leaders have the right to control the organization's resources. LMXD means that the allocation of resources will be affected by the relationship between leaders and employees, thus creating an unfair organizational atmosphere. ${ }^{23}$ Existing studies have shown that injustice in the workplace deviates from employees' expectations of the organization and will cause adverse emotional reactions and conflicts within the organization. ${ }^{24}$ There is a positive relationship between paradoxical leader behaviors and organizational citizenship behaviors. ${ }^{25}$ Work engagement has a mediating role between workplace loneliness and organizational citizenship behaviors. ${ }^{26}$

At the same time, according to the affective events theory, individuals' perceived work experience will trigger their emotional reactions, affecting the individual's psychology and behaviour and further affecting the organization's performance. ${ }^{27}$ As a signal that work events are inconsistent with personal goals, and employees often use negative emotions to alleviate the negative effects of emotions ${ }^{28}$ which ultimately leads to decreased performance. Empirical studies also show that when employees perceive the unfair atmosphere in the work environment, they will feel ostracized and alienated by leaders and are prone to negative emotions and work deviation behaviours, which will negatively impact employee performance. ${ }^{29}$ Therefore, this study believes that negative emotions may mediate between LMXD and safety performance. Based on this, hypothesis $\mathrm{H} 2$ is proposed:

$\mathrm{H} 2$ : Negative emotions play a mediating role between LMXD and safety performance.

\section{The Mediating Role of Work Engagement} Work engagement refers to individuals' high psychological and physical involvement in activities, including vitality, dedication, and concentration. ${ }^{30}$ Related studies show 
that the availability of job resources ${ }^{31}$ and organizational equity $^{32}$ are important factors affecting work engagement. Work resources contribute to realizing work-related goals $^{33}$ and are one of the main driving factors of work engagement. ${ }^{34}$ In the workplace, high-quality leadermember exchange is an essential channel for employees to obtain organizational resources. Members who establish a low-quality exchange relationship with their leaders will get fewer resources than those with a high-quality leadermember exchange. Because employees will compare themselves with their colleagues around them, the sense of unfairness brought by the differentiated allocation of resources will reduce their work enthusiasm and effort. ${ }^{35}$

Individual work attitudes influence work behaviour in an organization. As a positive work attitude, work engagement plays a vital role in improving work performance. Some scholars have found that work engagement positively affects satisfaction and job performance. ${ }^{36}$ According to the affective events theory, certain organizational events will trigger employees' emotions and directly impact individual behaviours and attitudes. ${ }^{37}$ Therefore, this study believes that LMXD will affect employees' work engagement and enthusiasm and ultimately decrease safety performance. Based on this, hypothesis H3 is proposed:

H3: Work engagement plays an intermediary role between LMXD and safety performance.

\section{The Mediating Chain Effect of Negative Emotion and Work Engagement}

This study believes that negative emotions can inhibit an individual's work engagement. As a positive force with motivation and perception, emotion significantly influences individuals' work enthusiasm and attitude. ${ }^{38}$ On the one hand, positive emotions contribute to constructing individuals' lasting resources, including physical, intellectual, psychological, and social resources, which bring indirect and long-term benefits to individuals. On the contrary, negative emotions affect employees' work experience, dampen their work passion, and inhibit their commitment to work. On the other hand, negative emotions will interfere with employees' attention to the current task. The processing depth of the current task will weaken or even stop so that employees cannot put more energy into the work. According to the affective events theory, there is a specific connection between the emotional events and emotional reactions experienced by employees at work and their attitudes and behaviours. ${ }^{39}$ The unfairness caused by LMXD will lead to negative emotions such as employee dissatisfaction and anger. It will inhibit the enthusiasm of employees to contribute to the organization, make them unable to concentrate on their work, and even induce counterproductive work behaviours, which is not conducive to the improvement of safety performance. Therefore, this paper believes that while LMXD affects employee safety performance, negative emotions and work engagement play a chain mediation role.

Based on this, hypothesis $\mathrm{H} 4$ is proposed:

H4: Negative emotions and work engagement play a chain mediation role between LMXD and safety performance.

\section{Moderating Role of Interpersonal Trust}

Interpersonal trust refers to the tendency of an individual to believe that other members or organizations can be trusted $^{40}$ and is usually divided into cognitive trust and emotional trust. ${ }^{41}$ This study believes that interpersonal trust can weaken the relationship between LMXD and negative emotions. Studies have shown that trust can improve employees' tolerance of wrong behaviours. ${ }^{42}$ Employees with high interpersonal trust can get a sense of security from leaders and colleagues and have a positive attitude towards events at work, thus reducing the probability of generating negative emotions. However, employees with low interpersonal trust are more likely to have exclusive cognitive bias, and the differential management style of leaders is easy to be regarded as unjust behaviour driven by selfishness. In this case, employees are more likely to have negative emotions. Therefore, this study predicted that different levels of interpersonal trust would affect the relationship between LMXD and negative emotions. Accordingly, hypothesis H5 is proposed:

H5: Interpersonal trust plays a moderating role between LMXD and negative emotions.

In summary, the author has five research focuses, ie, testing the negative impact of LMXD on safety performance. Examine the mediating role of negative emotions between LMXD and safety performance. Examine the mediating role of work engagement between LMXD and safety performance. Examine the intermediary effect of work engagement and negative emotions on the chain between LMXD and safety performance. Examine the moderating effect of interpersonal trust between LMXD and negative emotions. The hypothetical model is shown in Figure 1. 


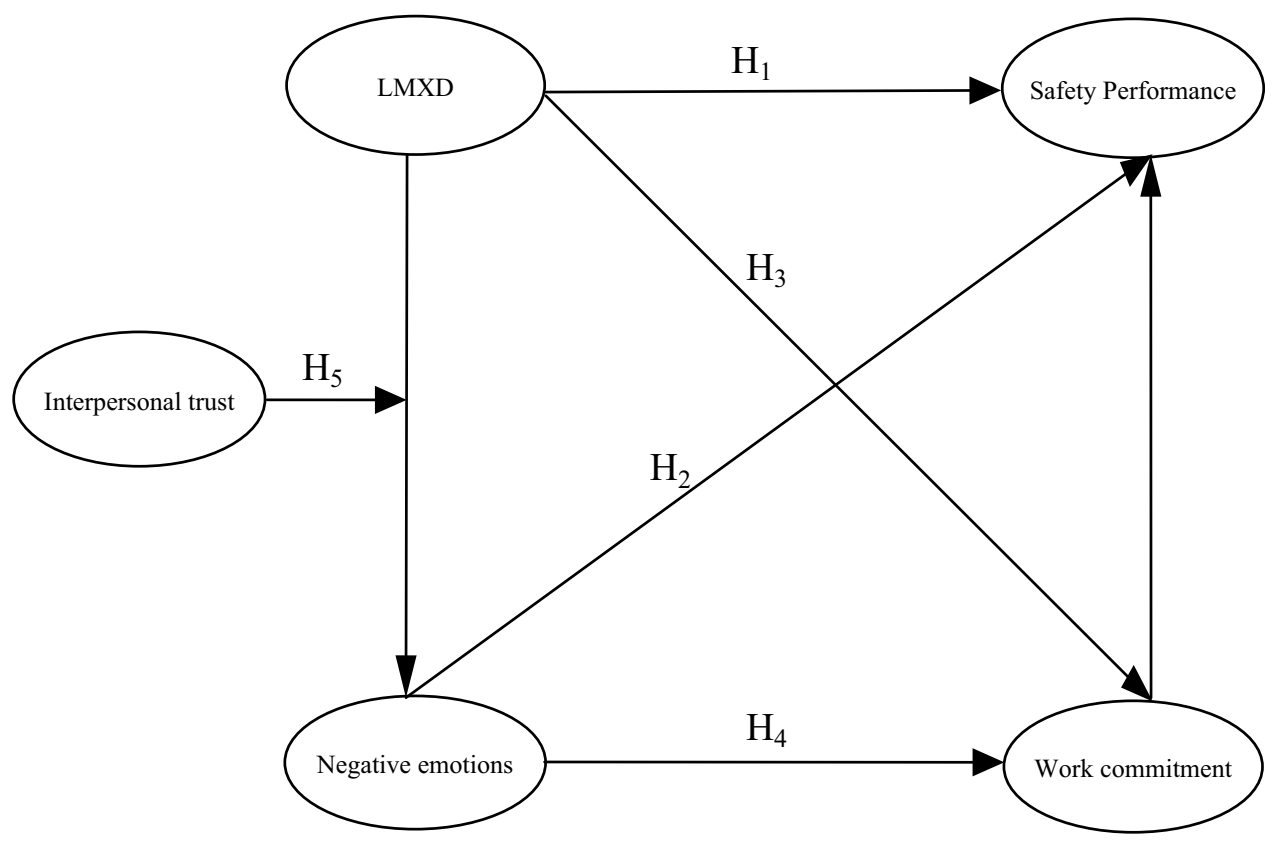

Figure I Theoretical framework.

\section{Research Methods}

\section{Sample and Procedure}

To verify the research hypothesis and clarify the relationship between LMXD, negative emotions, work engagement, and safety performance, SPSS and AMOS were used to test the mediating effect and the moderating effect. Based on stratified random sampling, five large construction companies in Liaoning Province were selected. We selected one large company based on the geographical distribution of the province and decided to distribute 80 questionnaires in each firm to achieve a sample size of 400 . This sample size was considered according to the sample size recommendations of Krejcie \& Morgan, ${ }^{2}$ as 384 respondents are sufficient in case of a large population. So, 400 questionnaires were issued, out of which 357 were valid questionnaires, with a recovery rate of $89.25 \%$. The data was collected from male gender; age is mainly 25 to 45 years, accounting for $86.2 \%$, and the working experience is mainly 1 to 5 years, accounting for $72.6 \%$. The education level of respondents is mainly junior college and below, accounting for $89.2 \%$; the sample mainly involves masons, plumbers, welders, plumbers, shelf workers, and other types of work. From the characteristics of the sample, the sample is well represented.

\section{Measures}

The predecessor's questionnaire was partially modified according to actual needs, and the final questionnaire structure validity and content validity were good. All questionnaires use Likert's five-level scoring $1 \sim 5$ respectively, representing very non-conforming, nonconforming, general, and conforming.

LMXD is based on the study of ERDOGAN and BAUER $;{ }^{15}$ it is measured by calculating the standard deviation of the leader-member exchange relationship scores evaluated by team members. It uses the leadermember exchange scale compiled by Graen and UhlBien. ${ }^{43}$ The overall Cronbach's $\alpha$ coefficient of the scale is 0.846 , and all data can reach an acceptable level.

\section{Interpersonal Trust}

Rotter ${ }^{44}$ Interpersonal Trust Scale was used to measure the moderating effect. The overall Cronbach's $\alpha$ coefficient of the scale is 0.825 , and all data can reach an acceptable level.

\section{Negative Emotions}

Watson et $\mathrm{al}^{16}$ emotions scale was adopted in this research. The scale's overall Cronbach's $\alpha$ coefficient is 0.912 , and all data can reach acceptable levels. Keeping this study's theoretical orientation and conceptualization, we have anticipated various dimensions of negative emotions such as being cared for, ashamed, hostile, and depressed at the workplace.

\section{Work Engagement}

Schaufeli et al ${ }^{30}$ work engagement scale has been adopted in this study. The overall Cronbach's $\alpha$ coefficient of the scale is 0.936 , and all data can reach an acceptable level. 


\section{Safety Performance}

Griffin and Neal ${ }^{45}$ safety performance scale is adopted to measure safety performance. The overall Cronbach's $\alpha$ coefficient of the scale is 0.853 , and all data can reach an acceptable level.

\section{Data Analysis and Discussion Assessment of Validity and Common Method Bias Test}

In this study, AMOS software was used to test the discriminative validity among variables for confirmatory factor analysis. As shown in Table 1, the five-factor model $\left(\chi^{2} / \mathrm{DF}=2.195, \mathrm{RMSEA}=0.053, \mathrm{CFI}=0.956, \mathrm{NFI}=\right.$ 0.964 , NNFI $=0.931$ ) showed better fitting effect than other alternative models, indicating that the measurement tools of five constructs had good discriminative validity. In addition, we calculated the AVE and CR of each variable to test the convergence validity. The results are shown in Table 2. AVE of each variable is greater than 0.5 , and the $\mathrm{CR}$ value is greater than 0.8 , indicating that the convergence validity of each variable is good.

Since this study adopted the self-report method to collect questionnaire data, it is necessary to detect common method deviation. We use the Harman single factor method to test the severity of the common method bias, and the results show that the first factor accounts for $32.5 \%$ without rotation, which does not exceed $50 \%$ of the total account. Therefore, there is no serious common method bias in this study.

\section{Means, Standard Deviations, and Correlation Matrices}

All the variables of the mean, standard deviation, and coefficient of correlation matrix as shown in Table 3 . The results showed that there was a significant negative correlation between LMXD and negative emotions. Work engagement, interpersonal trust, and safety performance are significantly positive correlations. The correlation
Table 2 Factor Analysis

\begin{tabular}{|l|l|l|}
\hline Factor & AVE & CR \\
\hline LMXD & 0.648 & 0.927 \\
Negative emotions & 0.589 & 0.934 \\
Work engagement & 0.523 & 0.908 \\
Interpersonal trust & 0.596 & 0.967 \\
Safety performance & 0.581 & 0.892 \\
\hline
\end{tabular}

Abbreviations: LMXD, Leader-Member Exchange Differentiation; NE, Negative Emotions; WE, Work Engagement; SP, Safety Performance.

between the variables is in line with the theoretical expectation and preliminarily supports the research hypothesis.

\section{Mediation Testing}

In this paper, the hierarchical regression method in software SPSS26.0 is used to test the hypothesis, and the results are shown in Table 4. According to model 2, there is a significant inverse correlation between LMXD and safety performance $(\beta=-0.241, \mathrm{P}<0.001)$, and hypothesis $\mathrm{H} 1$ is valid. According to model 5 and model 8, LMXD has a significant positive correlation with negative emotions $(\beta=0.228, \mathrm{P}<0.001)$, and negative emotions have a significant negative correlation with safety performance ( $\beta=-0.353, P<0.001$ ). According to model 3, after adding negative emotions, the effect of LMXD on safety performance was decreased $(\beta=-0.170, \mathrm{P}<0.005)$, but the mediating effect value was significant $(\beta=-0.314$, $\mathrm{P}<0.001)$, indicating that negative emotions played a mediating role between LMXD and safety performance. Hypothesis $\mathrm{H} 2$ was established. According to model 6 and model 10, LMXD has a significant negative correlation with work engagement $(\beta=-0.246, \mathrm{P}<0.001$ ), and work engagement has a significant positive correlation with safety performance $(\beta=0.401, \mathrm{P}<0.001)$. According to model 4, after adding work engagement, the effect of LMXD on safety performance was decreased $(\beta=-0.152, \mathrm{P}<0.005)$, but the mediating effect value was significant $(\beta=0.361, \mathrm{P}<0.001)$, indicating that

Table I Confirmatory Factor Analysis Results

\begin{tabular}{|l|c|c|c|c|c|}
\hline Model & $\chi^{2}$ /df & RMSEA & CFI & NFI & TLI \\
\hline Five factors: LMXD, NE, WE, SP, IT & 2.195 & 0.052 & 0.956 & 0.964 & 0.931 \\
Four factors: LMXD+NE, WE, SP, IT) & 2.966 & 0.074 & 0.841 & 0.805 & 0.881 \\
Three factors: LMXD+NE+WE, SP, IT) & 3.514 & 0.081 & 0.732 & 0.718 & 0.785 \\
Two factors: LMXD+NE+WE, SP+IT) & $5.7 I I$ & 0.063 & 0.654 & 0.635 & 0.647 \\
One factors: LMXD+NE+WE+SP+IT) & 7.821 & 0.154 & 0.465 & 0.574 & 0.432 \\
\hline
\end{tabular}

Abbreviations: LMXD, Leader-Member Exchange Differentiation; NE, Negative Emotions; WE, Work Engagement; SP, Safety Performance. 
Table 3 Correlation Analysis

\begin{tabular}{|c|c|c|c|c|c|c|c|c|c|c|c|}
\hline Variable & $\mathbf{M}$ & SD & I & 2 & 3 & 4 & 5 & 6 & 7 & 8 & 9 \\
\hline Age & 2.538 & 1.100 & I & & & & & & & & \\
\hline Education & 1.891 & 0.805 & -0.079 & 1 & & & & & & & \\
\hline Length of service & 2.062 & 0.832 & $0.136^{* *}$ & -0.074 & I & & & & & & \\
\hline LMX mean & 3.388 & 1.44 & 0.052 & -0.004 & 0.023 & I & & & & & \\
\hline LMXD & 0.473 & 0.128 & 0.047 & 0.019 & -0.046 & -0.016 & I & & & & \\
\hline Interpersonal trust & 3.055 & 1.624 & 0.032 & 0.025 & 0.021 & $0.116^{*}$ & $-0.365^{* * *}$ & I & & & \\
\hline Negative emotions & 3.439 & 1.503 & -0.059 & -0.021 & -0.061 & $-\left.0.16\right|^{* *}$ & $0.229 * * *$ & $-0.391 * * *$ & I & & \\
\hline Work engagement & 3.423 & 1.445 & 0.018 & -0.019 & 0.089 & $0.25 I^{* * *}$ & $-0.253 * * *$ & $0.307^{* * *}$ & $-0.223 * * *$ & I & \\
\hline Safety performance & 3.281 & 1.516 & 0.028 & -0.041 & 0.070 & $0.111 *$ & $-0.245^{* * *}$ & $0.325 * * *$ & $-0.363 * * *$ & $0.407 * * *$ & I \\
\hline
\end{tabular}

Notes: Path Coefficients: ***p 0.001 level, ${ }^{* *} p, 0.01$ level, ${ }^{*} p, 0.05$ level. $M$ is the mean; SD is standard deviation.

Abbreviations: LMX, leader-member exchange; LMXD, leader-member exchange differentiation.

Table 4 Mediation Effect

\begin{tabular}{|c|c|c|c|c|c|c|c|c|c|c|}
\hline \multirow[t]{2}{*}{ Variable } & \multicolumn{6}{|c|}{ Safety Performance } & \multicolumn{2}{|c|}{$\begin{array}{l}\text { Negative } \\
\text { Emotions }\end{array}$} & \multicolumn{2}{|c|}{ Work Engagement } \\
\hline & $\begin{array}{c}\text { Model } \\
\text { I }\end{array}$ & Mode 2 & Model 3 & Model 4 & Model 5 & Model 6 & $\begin{array}{c}\text { Model } \\
7\end{array}$ & $\begin{array}{c}\text { Model } \\
8\end{array}$ & $\begin{array}{c}\text { Model } \\
9\end{array}$ & $\begin{array}{l}\text { Model } \\
10\end{array}$ \\
\hline Age & 0.011 & 0.025 & 0.006 & 0.022 & -0.005 & 0.014 & -0.046 & -0.059 & -0.007 & 0.007 \\
\hline Education & -0.035 & -0.031 & -0.041 & -0.028 & -0.046 & -0.03 & -0.029 & -0.033 & -0.013 & -0.008 \\
\hline Length of service & 0.063 & 0.051 & 0.038 & 0.025 & 0.045 & 0.03 & -0.053 & -0.041 & 0.083 & 0.07 \\
\hline LMX mean & $0.109 *$ & $0.104 *$ & 0.056 & 0.016 & 0.053 & 0.008 & $-0.157^{* *}$ & $-0.153 * *$ & $0.250 * * *$ & $0.245 * * *$ \\
\hline LMXD & & $-0.241 * * *$ & $-0.170 * *$ & $-0.152^{* *}$ & & & & $0.228^{* * *}$ & & $-0.246 * * *$ \\
\hline Negative & & & $-0.314 * * *$ & & $-0.353 * * *$ & & & & & \\
\hline emotions & & & & & & & & & & \\
\hline Work engagement & & & & $0.361^{* * * *}$ & & $0.401 * * *$ & & & & \\
\hline R2 & 0.018 & 0.076 & 0.166 & 0.190 & 0.139 & 0.168 & 0.032 & 0.083 & 0.070 & 0.131 \\
\hline$\Delta \mathrm{R} 2$ & 0.018 & 0.058 & 0.090 & 0.114 & 0.121 & 0.150 & 0.032 & 0.051 & 0.070 & 0.060 \\
\hline $\mathrm{F}$ & 1.638 & $5.780 * * *$ & $11.639 * * *$ & $13.648^{* * *}$ & $11.355^{* * *}$ & $14.183^{* * * *}$ & $2.902 *$ & $6.389 * * *$ & $6.653 * * *$ & $10.542 * * *$ \\
\hline
\end{tabular}

Notes: ***p 0.001 level, **p, 0.01 level, *p, 0.05 level.

Abbreviations: LMX, leader-member exchange; LMXD, leader-member exchange differentiation.

work engagement played a mediating role between LMXD and safety performance. Hypothesis H3 was established.

The Process macro program of the SPSS plug-in was used to verify further the mediating role of negative emotions and work engagement between LMXD and safety performance and to check the interplay between the two in the chain. The results are shown in Table 5. The 95\% confidence interval of the mediation path of negative emotions is $[-1.222,-0.341]$, excluding 0 , indicating that the mediation effect is significant, and hypothesis H2 is further supported. The $95 \%$ confidence interval of the mediation path of work engagement is $[-1.316,-0.390]$, excluding 0 , and the mediation effect is also significant. Hypothesis H3 has been verified again. The 95\% confidence interval of the chain mediation path "LMXD $\rightarrow$ Negative emotions $\rightarrow$ Work engagement $\rightarrow$ Safety performance" is $[-0.306,-0.047]$, excluding 0 , indicating that

Table 5 Results of the Chain Mediation Test

\begin{tabular}{|l|c|c|}
\hline Chained Mediation Path & Effect & $\mathbf{9 5 \%}$ Cl \\
\hline LMXD $\rightarrow$ Negative emotions $\rightarrow$ Safety performance & -0.725 & {$[-1.222,-0.341]$} \\
LMXD $\rightarrow$ Work engagement $\rightarrow$ Safety performance & -0.810 & {$[-1.316,-0.390]$} \\
LMXD $\rightarrow$ Negative emotions $\rightarrow$ Work engagement $\rightarrow$ Safety performance & -0.152 & {$[-0.306,-0.047]$} \\
\hline
\end{tabular}

Abbreviations: LMX, leader-member exchange; LMXD, leader-member exchange differentiation. 
negative emotions and work engagement play a chain mediation role between LMXD and safety performance. Hypothesis H4 has been verified.

\section{Moderating Effect Test}

In SPSS 26.0, the hierarchical linear regression model is used to test the regulating effect, and the results are shown in Table 6. According to model 14, the product interaction term of LMXD and interpersonal trust has a significant negative prediction effect on negative emotions $(\beta=$ $-0.136, \mathrm{P}<0.005)$, indicating that interpersonal trust negatively regulates the relationship between LMXD and negative emotions. In addition, this paper draws a regulatory effect diagram to show the regulatory effect more clearly, as shown in Figure 2. As shown in Figure 2, LMXD has different slopes to negative emotions under different levels of interpersonal trust. When the employee has high interpersonal trust, the slope of the line is smaller than that of the employee with low interpersonal trust, which indicates that the negative impact of LMXD on employee safety performance is weaker, and H5 has been verified. Table 7 shows study hypothesis results.

\section{Study Limitations}

The limitations of this study are mainly reflected in the following aspects. First of all, the investigations in this study all come from a one-time point, and the future investigation of variables can be carried out from multiple periods. In particular, the relationship between leaders and employees may change with the change of time so that further research can be conducted from a dynamic perspective in the future. Secondly, this study only

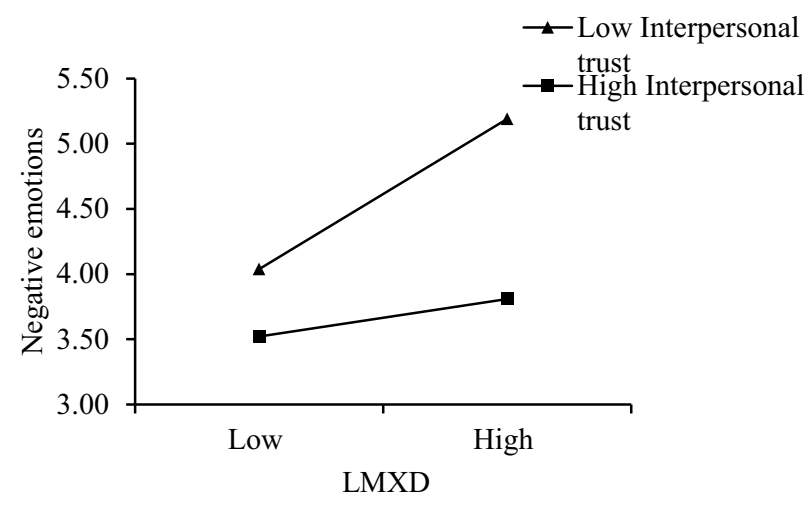

Figure 2 Interpersonal trust regulating “LMXD - Negative Emotions".

investigated Liaoning Province in China, and it remains to be verified whether the research conclusions are applicable to other regions. In addition, there is a significant cultural difference between enterprises. This study did not include the factors that potentially affect the relationship between superiors and subordinates in the corporate culture into the control variables, affecting the significant degree of the coefficients between relevant variables. Therefore, it is possible to consider including the variables related to corporate culture in the research on the relationship between superiors and subordinates in the future.

\section{Conclusion}

This study uses affective events theory, leader-member exchange theory, and conservation of resource theory to explore the internal mechanism and boundary conditions of LMXD on safety performance and examines the mediating effect of negative emotions and work engagement and the moderating effect of interpersonal trust. The main

Table 6 Moderating Effect Regression Analysis Results

\begin{tabular}{|l|c|c|c|c|}
\hline \multirow{2}{*}{ Variable } & \multicolumn{4}{|c|}{ Negative Emotions } \\
\cline { 2 - 5 } & Model II & Mode I2 & Model I3 & Model I4 \\
\hline Age & -0.046 & -0.062 & -0.046 & -0.055 \\
Education & -0.029 & -0.036 & -0.023 & -0.02 I \\
Length of service & -0.053 & -0.030 & -0.036 & -0.033 \\
LMX Mean & $-0.157^{* *}$ & $-0.127^{*}$ & $-0.106^{*}$ & -0.113 \\
LMXD & & $0.273^{* * *}$ & $0.140^{* *}$ & $0.159^{* *}$ \\
Interpersonal trust & & & $-0.317^{* * *}$ & $-0.317^{* * *}$ \\
Interpersonal trust LMXD* & & & & $-0.136^{* *}$ \\
R2 & 0.032 & 0.105 & 0.186 & 0.204 \\
SR2 & 0.032 & 0.073 & 0.081 & 0.018 \\
F & $2.902^{*}$ & $8.218 * * *$ & $13.342^{* * *}$ & $12.78 I^{* * *}$ \\
\hline
\end{tabular}

Notes: ***p 0.001 level, **p, 0.01 level, *p, 0.05 level.

Abbreviations: LMX, leader-member exchange; LMXD, leader-member exchange differentiation. 
Table 7 Hypothesis Results

\begin{tabular}{|l|l|c|}
\hline Hypothesis & Statement & Supported/Not Supported \\
\hline HI: & LMXD has a significant negative impact on safety performance. & Supported \\
H2: & Negative emotions play a mediating role between LMXD and safety performance. & Supported \\
H3: & Work engagement plays an intermediary role between LMXD and safety performance. & Supported \\
H4: & Negative emotions and work engagement play a chain mediation role between LMXD and safety performance & Supported \\
H5: & Interpersonal trust plays a moderating role between LMXD and negative emotions. & Supported \\
\hline
\end{tabular}

conclusions are as follows: LMXD has a significant negative impact on safety performance; Negative emotions and work engagement played a mediating role in the influence of LMXD on safety performance alone and played a mediating chain role together. Interpersonal trust negatively regulates the relationship between LMXD and negative emotions.

\section{Theoretical Contribution}

This study is the very first of its kind to explore the impact of LMXD on safety performance in the construction industry through the mediating role of work engagement and negative emotions. In recent years, the research on LMXD has gradually attracted the wide attention of scholars. However, the mechanism of LMXD on safety performance is still in the exploratory stage. Unlike previous studies, which mainly discussed the influence mechanism of leadership or employee factors on safety performance, this study first linked LMXD with safety performance from the perspective of the exchange relationship between leaders and employees and found that LMXD had a vital role impact on safety performance. The conclusion of this study not only verifies the effectiveness of LMXD, but also inspires more research on LMXD as an antecedent in the future.

In view of the lack of research on the mechanism of LMXD on safety performance, this study, based on the affective events theory, verifies the mediating effect and chain mediating effect between negative emotions and work engagement on LMXD and safety performance and opens the black box that LMXD has a negative impact on safety performance. Previous studies on LMXD rarely focus on the field of safety production, and the mechanism of LMXD's influence on safety performance is still unclear. This study selects two mediating variables, negative emotions, and work engagement, to explore the internal mechanism of LMXD's influence on safety performance through negative emotions and work engagement. The results show that LMXD can enhance employees' negative emotions and reduce work engagement, thus having a negative impact on safety performance. The discovery of the chain mediation mechanism is helpful to reveal further the process of LMXD affecting safety performance.

This study demonstrates that interpersonal trust is an important boundary condition of LMXD affecting safety performance. In the research on the effect of LMXD on performance, few scholars attach importance to the moderating role of psychological variables in the relationship between LMXD and performance. Based on interpersonal trust as a psychological variable, this study explored the moderating effect of interpersonal trust. It investigated the changing degree of LMXD's influence on safety performance under different levels of interpersonal trust. Therefore, this study enriches the research on boundary conditions of LMXD affecting safety performance.

\section{Practical Inspiration}

Leaders should pay attention to the negative impact of LMXD on safety performance. On the one hand, leaders should strengthen communication with employees, coordinate the relationship between team members, and avoid the potential harm of LMXD. On the other hand, leaders should set fair and reasonable standards to reduce employees' perception of differential treatment and reduce the negative impact of employee dissatisfaction on performance.

Leaders should pay attention to employees' negative emotions and work engagement. According to the research results, LMXD affects safety performance through negative emotions and work engagement. Therefore, leaders should monitor and evaluate employees' negative emotions and provide timely psychological counselling to employees with poor emotions to help them with their negative emotions. At the same time, leaders need to show more emotional care to employees and strengthen the interaction and emotional communication with employees to improve employees' work engagement more effectively. 
Leaders should create a working atmosphere of mutual trust. The findings suggest that low levels of interpersonal trust can make employees suspicious of each other, with negative consequences. Therefore, according to its situation, the organization should regularly hold team-building activities to promote the communication and communication of internal members to enhance the feelings of members. In addition, leaders should timely disclose relevant work information and make reasonable explanations to reduce misunderstanding and trust crises caused by information asymmetry and lag.

\section{Data Sharing Statement}

The data that support the findings of this study are available from the corresponding author upon reasonable request.

\section{Ethical Approval}

All participants gave their informed consent for inclusion before they participated in the study. All procedures performed were by the ethical standards as laid down in the 1964 Declaration of Helsinki and its later amendments or comparable ethical standard. All the procedures were approved by the ethical committee of School of Business Management, Liaoning Technical University, Huludao, China.

\section{Author Contributions}

All authors contributed to data analysis, drafting or revising the article, have agreed on the journal to which the article will be submitted, gave final approval of the version to be published, and agree to be accountable for all aspects of the work.

\section{Funding}

This research was supported by discipline innovation team of Liaoning Technical University(LNTU20TD-04) and Humanities and Social Science Fund of MOE (Ministry of Education of China)(19YJA630038).

\section{Disclosure}

The authors declare no conflicts of interest in this work.

\section{References}

1. Lee J, Huang Y, Cheung JH, Chen Z, Shaw WS. A systematic review of the safety climate intervention literature: past trends and future directions. J Occup Health Psychol. 2019;24(1):66. doi:10.1037/ ocp0000113

2. Martin R, Epitropaki O, Thomas G, Topakas A. A review of leadermember exchange research: future prospects and directions. In: Hodgkinson GP, Ford JK, editors. International Review of Industrial and Organizational Psychology. 2010:35-88. doi:10.1002/ 9780470661628.ch2
3. Henderson D, Liden R. BG-T leadership. LMX differentiation: a multilevel review and examination of its antecedents and outcomes. Leadersh Q. 2009;20(4):517-534. doi:10.1016/j. leaqua.2009.04.003

4. Weiss HM, Cropanzano R. Affective events theory. Res Organ Behav. 1996;18(1):1-74.

5. Haidan ZLLIUJZ, Wei LOU. Relationship between working attitude and performance of knowledge workers. Chinese $J$ Manag. 2008;1:149-155.

6. Feng W, Xiujuian L. The verification of the structure of the double-factor leadership and a study on their mechanisms that affect their promises to the organization. Manag World. 2008;5. Available from: https://en.cnki.com.cn/Article_en/CJFDTotal-GLSJ200805014. htm. Accessed September 14, 2021

7. Huang Y, He Y, Lee J, Hu C. Key drivers of trucking safety climate from the perspective of leader-member exchange: bayesian network predictive modeling approach. Accid Anal Prev. 2021;150:105850. doi:10.1016/j.aap.2020.105850

8. DeWall CN, Twenge JM, Bushman B, Im C, Williams K. A little acceptance goes a long way: applying social impact theory to the rejection-aggression link. Soc Psychol Personal Sci. 2010;1 (2):168-174. doi:10.1177/1948550610361387

9. Erdogan B. A justice perspective to understanding the effects of LMX differentiation for individual attitudes. National Meeting of the Academy of Management. Denver, CO; 2002.

10. Peng W, Fangwei Z, Haoyang S, Xiaona B. Interpersonal trust and knowledge hiding behavior: the joint moderating effects of the personal reputation concern and perceived uncertainty. Manage Rev. 2019;31(1):155.

11. Ferreira PMDN. Negotiation for the Middle East: a comparative study of cultures and the construction of a negotiation framework for Portuguese in Kuwait; 2017.

12. Dirks KT, Ferrin DL. The role of trust in organizational settings. Organ Sci. 2001;12(4):450-467. doi:10.1287/orsc.12.4.450.10640

13. He C, McCabe B, Jia G. Effect of leader-member exchange on construction worker safety behavior: safety climate and psychological capital as the mediators. Saf Sci. 2021;142:105401. doi:10.1016/j. ssci.2021.105401

14. Gooty J, Thomas JS, Yammarino FJ, Kim J, Medaugh M. Positive and negative emotional tone convergence: an empirical examination of associations with leader and follower LMX. Leadersh Q. 2019;30 (4):427-439. doi:10.1016/j.leaqua.2019.03.002

15. Erdogan B, Bauer TN. Differentiated leader-member exchanges: the buffering role of justice climate. J Appl Psychol. 2010;95:1104. doi:10.1037/a0020578

16. Watson D, Clark L, Tellegen A; social AT-J of personality and, 1988 undefined. Development and validation of brief measures of positive and negative affect: the PANAS scales. J Pers Soc Psychol. 1988;54 (6):1063-1070. doi:10.1037/0022-3514.54.6.1063

17. Cao Q-R, Li K, Liu L-N. Empirical study on impact of coalmine safety culture on miner's safety behavior. Zhongguo Anquan Kexue Xuebao. 2011;21(4):143-149.

18. Li AN, Liao H. How do leader-member exchange quality and differentiation affect performance in teams? An integrated multilevel dual process model. J Appl Psychol. 2014;99(5):847. doi:10.1037/ a0037233

19. Hobfoll SE. Conservation of resources: a new attempt at conceptualizing stress. Am Psychol. 1989;44:513-524. doi:10.1037/0003066X.44.3.513

20. Yuan L, Xiao S, Li J, Chen C, Ning L. Leader-member exchange differentiation and team member performance: the moderating role of the perception of organisational politics. Int $J$ Manpow. 2016;37:1347-1364. doi:10.1108/IJM-11-2014-0221

21. Mu X, Zhang H, Liu Z, Wei S, Guo Y, Qiao M. Effect of negative emotion on learning-memorizing ability. Med Recapitul. 2017;2017:24 
22. Chen Y, Tang M. Influencing mechanism of perceived competitive climate on employees' knowledge hiding. Sci Technol Prog Policy. 2018;17:131-138.

23. Lee J. Leader-member exchange, perceived organizational justice, and cooperative communication. Manag Commun Q. 2001;14 (4):574-589. doi:10.1177/0893318901144002

24. Farh CIC, Chen Z. Beyond the individual victim: multilevel consequences of abusive supervision in teams. J Appl Psychol. 2014;99 (6):1074. doi:10.1037/a0037636

25. Ren H, Yang R. Paradoxical leader behaviors and followers overall justice and citizenship behaviors: the role of renqing perception and trait agreeableness. Psychol Res Behav Manag. 2021;14:1303. doi:10.2147/PRBM.S324460

26. Tian G, Pu L, Ren H. Gender differences in the effect of workplace loneliness on organizational citizenship behaviors mediated by work engagement. Psychol Res Behav Manag. 2021;14:1389. doi:10.2147/ PRBM.S329959

27. Alam M, Singh P. Performance feedback interviews as affective events: an exploration of the impact of emotion regulation of negative performance feedback on supervisor-employee dyads. Hum Resour Manag Rev. 2019;31:100740.

28. Yuhui L, Zhen W, Canwei H, Luomeng W. The effects of abusive supervision on psychological distress and job performance: a moderated mediation. Manage Rev. 2016;28(2):127.

29. Duffy MK, Shaw JD. The Salieri syndrome: consequences of envy in groups. Small Gr Res. 2000;31(1):3-23. doi:10.1177/ 104649640003100101

30. Schaufeli WB, Salanova M, González-Romá V, Bakker AB. The measurement of engagement and burnout: a two sample confirmatory factor analytic approach. J Happiness Stud. 2002;3(1):71-92. doi:10.1023/A:1015630930326

31. Kotzé M, Nel P. The influence of job resources on platinum mineworkers' work engagement and organisational commitment: an explorative study. Extr Ind Soc. 2020;7(1):146-152.

32. $\mathrm{Li} \mathrm{J,} \mathrm{Xu} \mathrm{B,} \mathrm{Chen} \mathrm{J.} \mathrm{The} \mathrm{effect} \mathrm{of} \mathrm{organizational} \mathrm{factors} \mathrm{on} \mathrm{job}$ engagement. Chinese J Appl Psychol. 2006;12(2):176-181.

33. Boon C, Kalshoven K. How high-commitment HRM relates to engagement and commitment: the moderating role of task proficiency. Hum Resour Manage. 2014;53(3):403-420. doi:10.1002/ hrm. 21569

34. Tims M, Bakker AB, Xanthopoulou D. Do transformational leaders enhance their followers' daily work engagement? Leadersh $Q$. 2011;22(1):121-131. doi:10.1016/j.leaqua.2010.12.011
35. Zhong L, Fan M, Chen L, et al. Both the property of resource and medium of exchange matter: what's fair for goods is unfair for money. Acta Psychol Sin. 2014;46(9):1392. doi:10.3724/SP. J.1041.2014.01392

36. Dubbelt L, Demerouti E. The value of job crafting for work engagement, task performance, and career satisfaction: longitudinal and quasi-experimental evidence. Eur J Work Organ Psy. 2019;28 (3):300-314. doi:10.1080/1359432X.2019.1576632

37. Weiss HM, Cropanzano R. Affective events theory: a theoretical discussion of the affective experiences and job satisfaction and variations in affective experience over time. December Organ Behav Hum. 1996;78:1-24.

38. Leeper RW. The motivational and perceptual properties of emotions as indicating their fundamental character and role. In: Feelings and Emotions. Elsevier; 1970:151-168.

39. Reynolds Kueny CA, Francka E, Shoss MK, Headrick L, Erb K. Ripple effects of supervisor counterproductive work behavior directed at the organization: using affective events theory to predict subordinates' decisions to enact CWB. Hum Perform. 2020;33 (5):355-377. doi:10.1080/08959285.2020.1791871

40. Tsai J, Hung SY.Examination of community identification and interpersonal trust on continuous use intention: evidence from experienced online community members. Info Manag.2019;56:552-569. doi:10.1016/j.im.2018.09.014

41. McAllister DJ. Affect- and cognition-based trust as foundations for interpersonal cooperation in organizations. Acad Manag J. 1995;38 (1):24-59. doi:10.5465/256727

42. Colquitt JA, Scott BA, LePine JA. Trust, trustworthiness, and trust propensity: a meta-analytic test of their unique relationships with risk taking and job performance. J Appl Psychol. 2007;92(4):909-927. doi:10.1037/0021-9010.92.4.909

43. Graen GB, Uhl-Bien M. Relationship-based approach to leadership: development of leader-member exchange (LMX) theory of leadership over 25 years: applying a multi-level multi-domain perspective. Leadersh Q. 1995;6(2):219-247. doi:10.1016/1048-9843(95)90036-5

44. Rotter JB. A new scale for the measurement of interpersonal trust. J Pers. 1967;35:651-665. doi:10.1111/j.1467-6494.1967.tb01454.x

45. Griffin M, Neal A. Perceptions of safety at work: a framework for linking safety climate to safety performance, knowledge, and motivation. J Occup Health Psychol. 2000;5:347. doi:10.1037/10768998.5.3.347
Psychology Research and Behavior Management

\section{Publish your work in this journal}

Psychology Research and Behavior Management is an international, peer-reviewed, open access journal focusing on the science of psychology and its application in behavior management to develop improved outcomes in the clinical, educational, sports and business arenas. Specific topics covered in the journal include: Neuroscience, memory and decision making; Behavior modification and management; Clinica applications; Business and sports performance management; Social and developmental studies; Animal studies. The manuscript management system is completely online and includes a very quick and fair peer-review system, which is all easy to use. Visit http://www. dovepress.com/testimonials.php to read real quotes from published authors. 